\title{
Defects of the building and its remediation - Case study: Elementary school Vodňany
}

\author{
Martin Dědič ${ }^{1, *}$ \\ ${ }^{1}$ Faculty of Technology, The Institute of Technology and Business, Okružní 517/10, 37001 České \\ Budějovice, Czech Republic
}

\begin{abstract}
The aim of the paper is to provide information on the defects in the construction of the elementary school in Vodñany. The building of the elementary school dates back to 1973 . It is a reinforced concrete columns skeleton with a filling peripheral and internal dividing brick masonry. The object is used by the primary school and is permanently used and maintained. The extent of structural damage is stabilized in the current state and is not an immediate risk to the user of the object. It concerns only non-load-bearing structures (floor and partitions), the vertical load-bearing structures do not show a decrease and therefore the stability of the whole building is not compromised. However, actual damage complicates operation of elementary school and is very non-aesthetic. Concurrent damage to structures is the result of vertical deformation of the foundation soil. Vertical deformation of the foundation soil - sediment is the result of the building construction on a former creek which was not properly excavated and covered with a suitable backfill. Subsidence further strengthens imperfect drained rainwater from the roof of the building and leakage of rainwater drains.
\end{abstract}

\section{Introduction}

Many buildings are constructed with foundations that are inadequate for the soil conditions existing on the site. Because of the lack of geographically convenient suitable land, homes are often built on marginal land that has insufficient bearing capacity to support the substantial weight of a structure. Land becomes scarce with the growth of cities, and it often becomes necessary to construct buildings and other structures on the sites with unfavourable conditions. [1]

Our task was to find out the state and defects of the building structures in the school premises - Primary School and Gymnasium Vodnany Branch - Bavorovska Street, Bavorovska 1046, Vodnany. In particular, focus on the extent of defects and damage, possible disasters, the correctness of the execution of the construction work in accordance with the general technical requirements for construction and technical regulations according to individual manufacturers, etc. Further assessment of the necessity to eliminate these failures.

Primary School Bavorovska Street is a building from 1973. It is a reinforced concrete column skeleton with a filling peripheral and internal dividing brick masonry. The building is maintained and is used by the primary school.

The initial study of the situation and the subsequent local investigation should therefore assess the way in which the situation can be adjusted so that the school space can be reused without difficulty, in order to avoid worsening of existing problems and recurrent defects.

\footnotetext{
* Corresponding author: dedic@mail.vstecb.cz
} 
Alternatively, propose corrective procedures that will correct the problems caused and prevent existing defects from widening.

Our goal was:

- Check for damage to floor structures

- Detection of damage to vertical vertical partition structures - partition walls

- determine the state of soil and causes of subsidence

- determine whether the drop in the underlying soil is the result of incomplete extraction of the old stream bed

- Design procedures for rehabilitation of existing structures

- propose a procedure for remediation of the subsoil leading to the avoidance of sedation

\section{Data retrieval}

Photo-documentation of facts and fact-finding was made. In the premises of the entrance pavilion, damaged floor structures were investigated. Floor structures are locally sinked and bent. The surface layer of the floors is ceramic tile squares and rectangular templates. The surface layer shows signs of long-term use but is not damaged by the deformation of the whole floor structure. Further, in the premises of the entrance pavilion, the research team investigated the damage of the vertical masonry dividing structures. These are brick partitions tl. $125 \mathrm{~mm}$ brick made of bricks CDm. Partitions show a large amount of cracks. These are sloping cracks passing through the joints and the mass of bricks and are caused by the seating of the foundation structures. Further, the partitions exhibit horizontal cracks and cracks at the joining points of the partition on the ceiling structure resulting from the mutual tearing of the structures apart. According to the documentation presented, the partitions are based on low trapezoidal base treads.

Some partitions are in a state of emergency, and if the situation is not addressed in the near future, they could be dangerous to the user. Reinforced concrete pillars and bearing walls do not show any signs of breakage from the laying of foundation structures. In the local survey, it was found that the elementary school building was based on the site where the brook brook was before the start of the construction. The brook was transferred and the original trough was to be mined and packed with sandy gravel. This statement was confirmed by the construction drawings where the original route of the stream, which led directly below the entrance hall of the building, was drawn. Furthermore, it was found that part of the rainfall is not drawn into the rainwater drainage or into a creek, but freely to the terrain. It was found that the rainwater drainage is led by the site where the original creek route was. If the sewer is leaking, it can be another source of sinking and sedimentation underneath the entrance hall. Geological exploration, surveying, camera drainage and georadar subsoil measurements were carried out on site.

\subsection{Research questions and answers}

Question No. 1 - To the object of the entrance hall of Bavorovska (object of the entrance pavilion) to determine the extent of the damage of the floor structures, the brick vertical dividing structures and the reason for their damage.

Question No. 2 - Consider whether the extent of damage to the entrance hall for the elementary school is trouble-free and safe. Next, consider whether structural damage can be deepened when ignoring the problem.

Question No. 3 - Identify the state of the ground and sewer under the entrance pavilion and identify the causes of the current state. 
Question No. 4 - Assess whether the subsoil and sewerage can be rehabilitated under the entry pavilion and, if appropriate, suggest a method of remediation.

Question No. 5 - Assess how the situation can be adjusted so that the entry pavilion can be brought into a stabilized state and possibly propose a technological process of remediation of all damaged structures

\subsubsection{NO.1}

Floor structures have been showing signs of bending and forfeiting locally from the first view. Deflection measured at several points in the building level is 10 to $45 \mathrm{~mm}$. Floating floor layers are ceramic tiles - square and rectangular templates. The strike layer is a sign of long-term use, but it is not damaged by deformations caused by the deflection of the floor. The reason for the deflection of the floor structures is the decrease of the foundation slab due to the vertical deformation of the foundation soil - sitting. Vertical brick construction $125 \mathrm{~mm}$ - the partitions are made of brick CDm. The partitions are based on low trapezoidal passports and show a large amount of cracks. These are cracks both vertical and horizontal. Vertical cracks go in some places both perpendicularly to the ground and obliquely and pass through the joints and the brick. Horizontal cracks occur especially in the area of the connection of partitions on the ceiling structure. The crack width ranges from 1 to $10 \mathrm{~mm}$. Because the cracks are located in the masonry walls, they are not statically cracked and do not endanger the safety of the building. The reason for the occurrence of oblique cracks is the decrease of the base passages due to the vertical deformation of the foundation soil - sitting. Horizontal cracks in the partition of partitions on the ceiling structure are the result of the partitioning of the partitions from the ceiling structures due to the fall of the basepasses and the seating of the foundation soil. The cracks in the building show different properties and therefore the research team will not allow to say whether it is a sudden or gradual sit of the foundation soil.

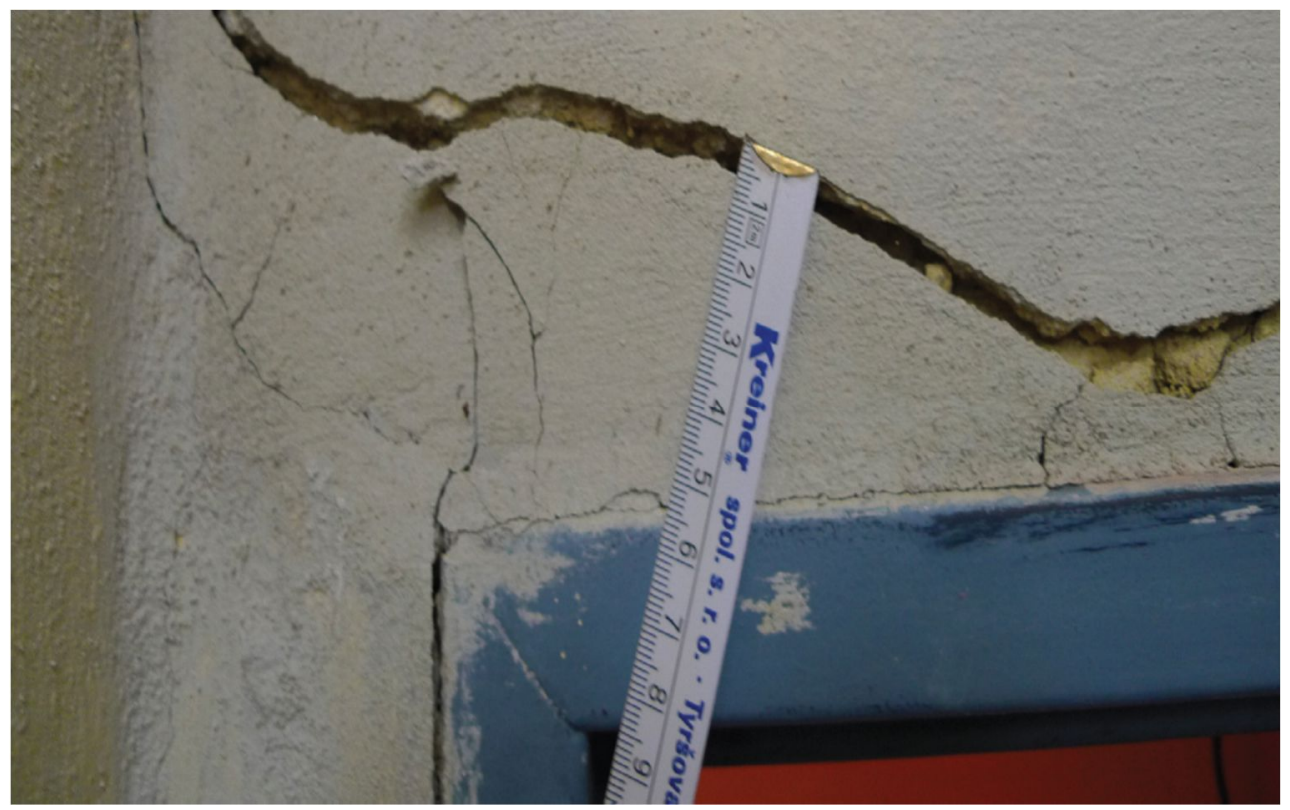

Fig. 1. Defects on the vertical structure 


\subsubsection{NO.2}

We have found that damage to the entrance pavilion is problematic. Due to drops of partitions, door wings and door frames must be repeatedly repaired and cracks repaired. Bent floor structures destabilize furniture assemblies, and unevenness complicates cleaning. These damages are so great that it is not just aesthetic defects but operating and user defects. Regarding the impact of structural damage on user safety, we note that the extent of the fall and cracks is now stabilized and there is no immediate threat to people. However, this claim must not continue to apply in future conditions, and the situation may continue to deteriorate undesirably as a result of further instability of the subsoil. Now the situation is stabilized and there is no need to declare the facility inoperable. However, the situation needs to be addressed according to the following recommendation recommendations.

\subsubsection{NO.3}

The research team gave a geological report on the subsoil beneath the entrance pavilion. The processor carried out two excavate probes at the site of the old stream creek, in front of the southern and northern side of the entrance pavilion. According to the geological survey, the two troughs were encountered with the old trough of the former creek, which was transferred. In the southern part around S2, the channel is 1.6 meters deep, and in the northern area around S1 it is already 2.0 meters deep. In addition, in the northern part around the S1 probe, it was found that the overflow of the trough was made by a totally inappropriate mixture of building material, clay and wet organic brooks with the content of wood chips. Probably the creek, without its extraction, was included in the coastal rotting organic sediments. Conversely, in the southern part around the S2 probe, these weights are dry and less organic. In the bedrock were found part of a clay with a low plasticity with peat content and deeper sands with a fine grain soil admixture with gravel content of up to $20 \%$. It was also found that part of the eaves from the roofs of the school is not drawn into the rainwater drainage or in the translated stream, but freely to the terrain, just in the area where the former stream passes, then this water drains and the humidity of the ballast increases their uneven sedation. It was also found that the rainwater sewerage, which leads through the old stream creek, is leaky and segmented in several places according to the sewerage test. The rainwater drainage is likely to run away from the water drained by the old stream stream. The rooms where the buildings are sitting are exactly the same as the course of the old creek. We suppose that in the place of the largest seating of the buildings, as well as in the S1 probe, the organic banks of the brook have brooks with fragments of branches and, moreover, they are occasionally infested with an inappropriate catchment of rainwater. These organic sediments sit at a different speed than the surrounding sands, and in addition, the organic substances gradually melt and degrade, which in the wet state enhances sedation.

The reason is that it is most important from the point of assessing subsidence of buildings and expresses the characteristics that we call compressibility. It is evident that differences in the modulus of deformation are very important, among the classes of finegrained, sandy and gravelly soils. [2]

From this trend it is apparent that the geological conditions have different characteristics in terms of impact on the subsidence of buildings in these important groups of sediments. [2] 


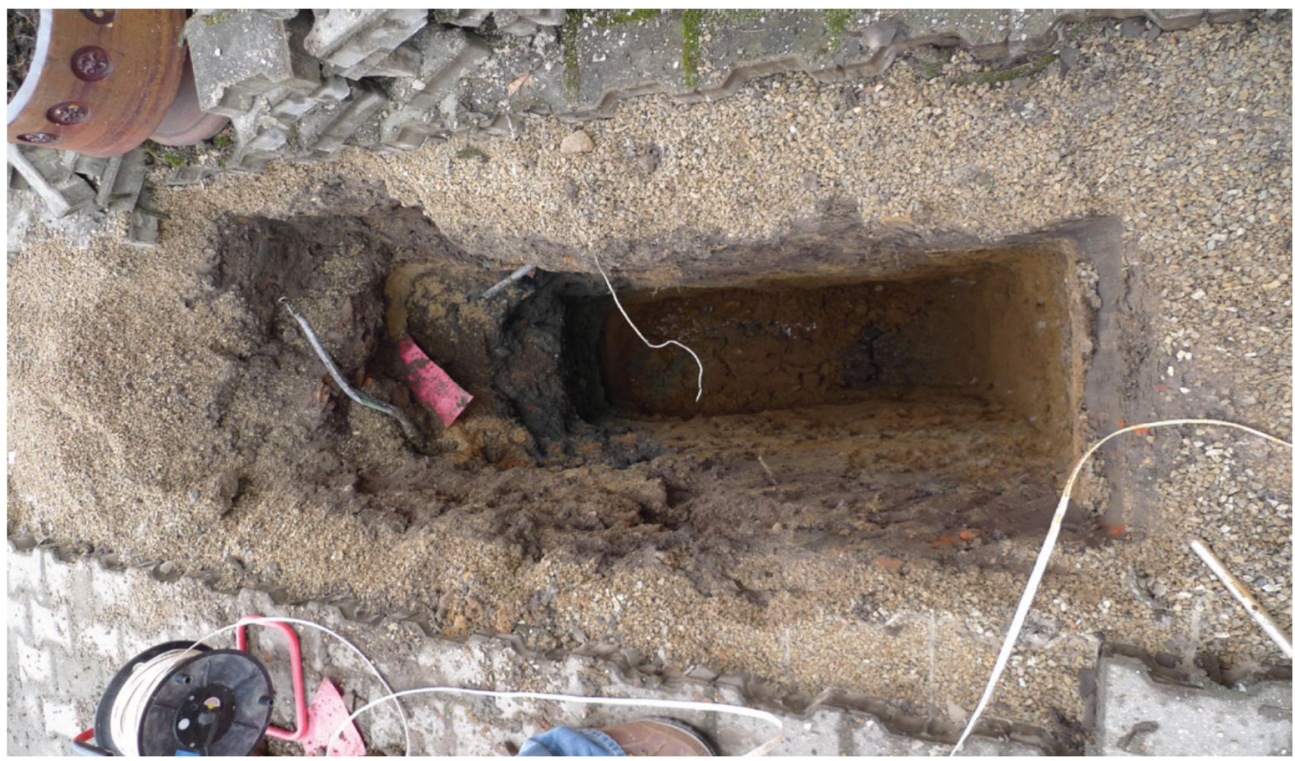

Fig. 2. Defects on the vertical structure

\subsubsection{NO.4}

As a possible correction of the current condition of the subsoil and sewerage it can be stated:

- Inappropriate soil should be removed from the original bed beneath the entrance pavilion and replaced with compacted gravel. This will ensure that any water can flow beneath the entrance pavilion and will not get anywhere

- to carry out an expert review of the sewerage system and, on the basis of the facts, to propose a suitable technological procedure for sewerage repairs

- Connect all roof drains to the rainwater drain so that the rainwater does not flow freely to the terrain

\subsubsection{NO.5}

The defects in the entrance vestibule are, according to available information, caused by an incorrect procedure for the remediation of the former creek before the building itself. The load-bearing structure itself is based more deeply on foundation feet and is stable.

Seating of inappropriate and insufficiently compacted layers under the floor of the vestibule caused the floor to drop, especially in the area of social facilities, where the floor is additionally loaded with masonry partitions. The drop area is roughly in the lane between the supporting columns (between the 2nd and 3rd columns from the left when viewed from the entrance) practically across the entire length of the input object.

Since the geological survey revealed inadequately selected and insufficiently compacted layers at the site under consideration, it is not possible to repair only above the floor level. For the good elimination of the cause of sedation I propose the following procedure:

- removing the masonry partition in the lane concerned

- cut the floor beyond the observed drop

- Remove the floor layers

- Choose unsuitable soil - humous and compacted layers 
- remediated the waste pipe in the space concerned - directionally correct and in particular the height, or to replace modern material

- fill up to $20 \mathrm{~cm}$ maximum with compaction by hand vibrating plate

- restoring the floor layers including the waterproofing - the exact procedure can be designed only after the actual floor layers have been found

- Restoration of partitions, preferably from lighter masonry

\section{Conclusion}

Concurrent damage to structures is the result of vertical deformation of the foundation soil. Vertical deformation of the foundation soil - sediment is the result of the construction of a former creek, which was not properly excavated and filled with suitable backfill. Sitting further strengthens imperfect drained rainwater from the roof of the building and leakage of rainwater drains.

The extent of structural damage is stabilized in the current state and is not an immediate risk to the user of the object. It concerns only non-load-bearing structures (floor and partitions), the vertical load-bearing structures do not show a decrease and therefore the stability of the whole building is not compromised. However, actual damage is complicated by operation and is very unsteady and very unsuitable for the operation of elementary schools.

The research team notes that the building is operational at the current state of the damage, but this must not be the case in the future, with further subsoil degradation, and the damage will continue to grow unpredictably. Therefore, it is necessary to solve the situation according to the recommendations of the report.

Exogenous and endogenous factors are interconnected and together affect terrain morphology, rock properties, groundwater, and many others. [4]

The reconstruction of damaged structures and subsoil is recommended by the expert as a complex construction activity, which will be preceded by the correct decisions in the order: assignment, investment balance, eventual project or technical solution, selection of the control mechanism (technical supervision of the investor, expert).

To ensure the perfect use of the entrance hall of the Primary School and the Gymnázium Vodnany Branch - Bavorovska Street, Bavorovska 1046, Vodnany, the following modifications are necessary: see point NO 1-5

Qualitative assumptions for the construction are determined by these documents in the sequence of their continuity:

- Object documentation with corrective measures, CSN, if specifically in the project or PD as a binding technical regulation, recommended measures and technological procedures of manufacturers and suppliers of building materials and by profession.

\section{References}

1. M. Marschlako, I. Yilmaz, L. Fojtová, K. Kubečka, T. Bouchal, M. Bednárik, The Scientific World Journal, 2013, 454710 (2013)

2. L. Podolka, M. Karková, R. Kampf, Evaluation an Indicate Moduls of Deformation for Fine-grained World Multidisciplinary Earth Sciences symposium, 1-5 (2016)

3. T. Vondráčková, S. Škoda, J. Vlček, Procedia Earth and Planetary Science: The World Multidisciplinary Earth Sciences Symposium, WMESS 2015, 15, 49-53 (2015) 